\title{
高漲度塩化ナトリウムと硝酸ナトリウム水溶液中における ステンレス鋼のアノード溶解挙動*
}

\author{
山本唀 夫**, 伊 東 祐 光**
}

\author{
Anodic Dissolution Behaviors of Stainless Steel in \\ Concentrated $\mathrm{NaCl}$ and $\mathrm{NaNO}_{3}$ Aqueous Solutions*
}

\author{
Hideo YAMAMOTO** and Sukemitsu ITO**
}

\begin{abstract}
Anodic behaviors of stainless steel (SUS 304) in $\mathrm{NaCl}$ and $\mathrm{NaNO}_{3}$ solutions were investigated by a galvanostatic method under various conditions of electrolysis, $i$. $e$. current densities of $5 \sim 40 \mathrm{~A} / \mathrm{cm}^{2}$, electrolyte concentrations of $100 \sim 400 \mathrm{~g} / l$, temperature of $10 \sim 70^{\circ} \mathrm{C}$, and electric quantities of $150 \sim$ $1,500 \mathrm{coulombs} / \mathrm{cm}^{2}$. Anodic polarization curves of stainless steel in these solutions were also taken by a potentiostatic method. It was confirmed that stainless steel dissolved as $\mathrm{Fe}^{2+}, \mathrm{Cr}^{3+}$ and $\mathrm{Ni}^{2+}$ ions in $\mathrm{NaCl}$ electrolyte, and as $\mathrm{Fe}^{3+}, \mathrm{Cr}^{6+}$ and $\mathrm{Ni}^{2+}$ ions in $\mathrm{NaNO}_{3}$ electrolyte. The current efficiency for the dissolution of stainless steel in these electrolytes was approxmately 100\%. The dissolution in $\mathrm{NaCl}$ electrolyte produces pitted, bright surfaces and in $\mathrm{NaNO}_{3}$ electrolyte etched, dull surfaces. When $\mathrm{NaNO}_{3}$ was added to $100 \mathrm{~g} / l \mathrm{NaCl}$ electrolyte, the valency of the dissolved ions was found to be $\mathrm{Fe}^{3+}$ for iron and $\mathrm{Cr}^{6+}$ for chromium at $\mathrm{NaNO}_{3}$ concentrations more than $8 \mathrm{~g} / l$. Only the active dissolution was observed in the anodic polarization curves for stainless steel in $\mathrm{NaCl}$ solution, while the stable passive and transpassive regions were observed in $\mathrm{NaNO}_{3}$ solutions.
\end{abstract}

1 緒 言 (Introduction)

電解加工の電気化学的な基礎研究としては，金属のア ノード分極曲線とその不働態皮膜に関する報告が多く知

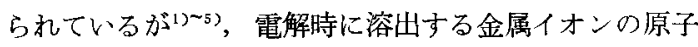
価の洒数について，詳細に取り扱ったものはほとんどな い. 近年, この価数に関しては, 電解液の種類および加 工材料の材翼等によって，異なることが予想されるた め，洒数の解明が強く望まれている。とくに従来の加工 理論抢よび加工技術を再検討寸る場合には，価数の決定 が重要な条件になるものと考えられる。

そこで本報告では，電気化学的な観点から活性態扔よ び過不働態領域での溶出金属イオンの価数についてはあ

・くすることを目的とした。金属にはステンレス鎆を用 い, 電解液として性金属に対して活性化扔よび過不働態 化の作用に著しい相異のみられる $\mathrm{NaCl}$ および $\mathrm{NaNO}_{3}$ を選んで,アノード溶解を行った・実験は各種の電解条

* 昭和48年10月11日電気化学協会北陸支部大会（金沢）にて発表

** 工業技術院譏杨技術研究所(東京都杉並区井草 4-12-1) Mechanical Engipeering Laboratory (12-1, Igusa 4-chome, Suginami-ku. Tokyo)
件下における金属の溶出量㧍よびその通電量から，溶出 金属イオンの原子価を推定し，さらに溶解面の形状など も調べた。また分極曲線の測定を行い，上記の結果との 関連性について考察した.

\section{2 実験方法 (Experimental)}

電解液は試薬一級の $\mathrm{NaCl}, \mathrm{NaNO}_{3}$ をそれぞれ所定 の港度にした水溶液であるが，一部実験にはこれらの混 合液を使用した．試料電極にはステンレス鋼棒材 SUS 304 (C 0.08, Si 0.45, Mn 0.80, P 0.028, S 0.009, Ni 8.46, Cr $18.92 \%$ ) を $5 \phi \times 7 \mathrm{~mm}$ の円柱形に加工 して用いた．前処理にはエメリ一研摩紙で 600 番まで順 次研摩し, さらに $0.3 \mu$ のアルミナ水溶液でバフ研摩し たのち,アセトンとアルコールで脱脂, 洗浄して試験に 供した。なお，この試料電極は露出面積 $0.2 \mathrm{~cm}^{2}$ で他 の部分がすべて絶縁物により被覆されている．対極には 白金黑付白金板を用い，かく注んを行わずに定電流法で ステンレス䤲を溶解した。

実験は，電解条件として，たとえば電流密度（5４0 
$\left.\mathrm{A} / \mathrm{cm}^{2}\right)$, 通電量 $\left(150 \sim 1,500 \mathrm{C} / \mathrm{cm}^{2}\right)$, 電解液の濃度 $(100 \sim 400 \mathrm{~g} / l)$ および温度 $\left(10 \sim 70^{\circ} \mathrm{C}\right)$ などを変えて行 った. 各種金属汶対する溶出量は，電解後，この電解液 を一夜間放置してから，湿式化学分析法で定量した。す なわち， $\mathrm{Fe}, \mathrm{Cr}, \mathrm{Ni}$ などはそれぞれ ン法, ジフェニルカルバジド法拉よびジメチルグリオキ シム法を適用して求めた。 また陚料電極材の熱処理につ いては，加工のます試片と $1,050^{\circ} \mathrm{C}$ で $30 \mathrm{~min}$ 溶体 化処理したものと比較したが，上記の実験結果には差異 が認められなかったので，熱处理は行わなかった。

溶出金属イオンの原子価の価数は $\mathrm{Fe}, \mathrm{Cr}, \mathrm{Ni}$ の溶出 原子価の組み合わせを数種仮定して，理論的に計算した 電気量 (溶出量：電気化学当量) を求如, これらの值と 実際の通電量との比較によって推定した.この際通電量 はデジタル電量計 (北斗電工製 CLM-2 型) によって求 めた.アノード分極曲線の測定は既報占に従った。

\section{3 結果および考察 (Results and Discussion)}

\section{1 通電量による変化}

Fig. 1 および 2 は $\mathrm{NaCl}$ および $\mathrm{NaNO}_{3}$ 電解液中で ステンレス鋼 SUS 304 を溶解させたとき，鋼構成各種 金属の溶出量と通電量の関係をそれぞれ示す. 溶出量は 通電量に比例していずれも増大するが，Fig. 1 および 2 では同一通電量でもその溶出量に顕著な相異が認ぬられ る.これらの結果は, 電解液をか人注んしてもほとんど 差が認められない，通電中電極からのガス発生量:測定 しなかったが，肉眼で観察した結果では，試料電極での ガス発生は非常に少く,アノード反応に対寸る電気量が ほとんど金属の溶解に消費されるものと考えられる。し

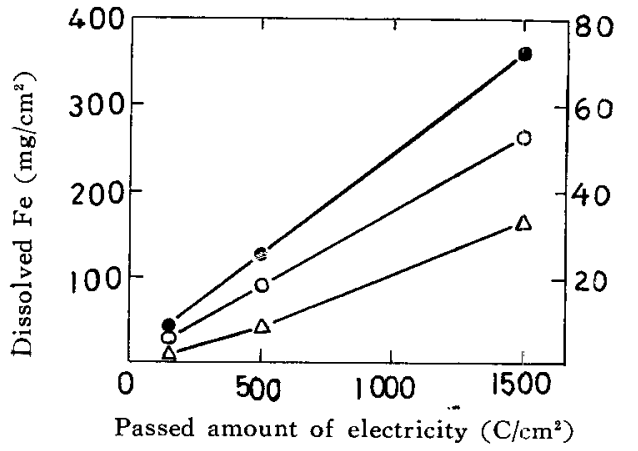

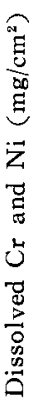

Fig. 1 Relation between passed amount of electricity and dissolved metals for stainless steel anode in $100 \mathrm{~g} / l \mathrm{NaCl}$ solution at $25^{\circ} \mathrm{C}$

$$
\begin{aligned}
& \mathrm{O}: \mathrm{Fe}, \quad \mathrm{Cr}, \triangle: \mathrm{Ni} \\
& \text { Current density }: 10 \mathrm{~A} / \mathrm{cm}^{2}
\end{aligned}
$$

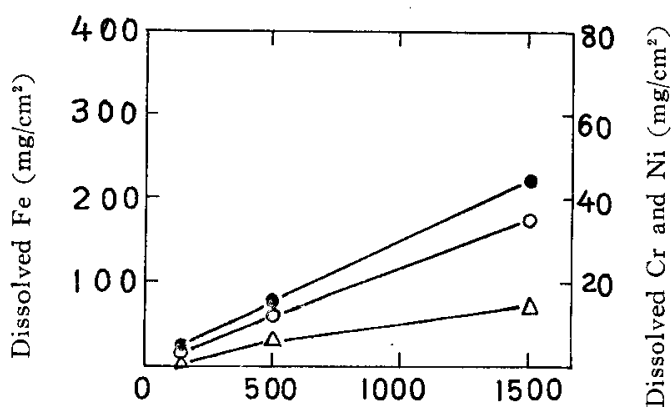

Passed amount of electricity $\left(\mathrm{C} / \mathrm{cm}^{2}\right)$

Fig. 2 Relation between passed amount of electricity and dissolved metals for stainless steel anode in $200 \mathrm{~g} / l \mathrm{NaNO}_{3}$ solution at $25^{\circ} \mathrm{C}$

$$
\mathrm{O}: \mathrm{Fe}, \quad \mathrm{Cr}, \quad \triangle: \mathrm{Ni}
$$

Current density : $10 \mathrm{~A} / \mathrm{cm}^{2}$

たがってこの場合金属の溶解の電流效率は $100 \%$ と見な す．また著者らはこの理由として，密閉系の電解セルを 用いて，パルス電解法で定電流溶解した際，上記電極に おける酸素発生（酸素量はガスクロマトグラフィーによ る定量）に対する電流効率が非常に低い值 $\left(10 \mathrm{~A} / \mathrm{cm}^{2}\right.$ で は $\mathrm{NaNO}_{3}$ 中で 2 3\%, $\mathrm{NaCl}$ 中で $1 \%$ 以下を示す) になることを確認している . 他方, 対極からはガスの発 生が顕著に観察される. Table 1 は Fig. 1 および 2 に おける溶出量より金属イオンの原子価を種々仮定して算 出したステンレス鋼溶解の電流効率を示寸。これらの結 果から， $\mathrm{NaCl}$ 電解液に扔いてはアノード溶解によって 溶出する各金属イオンの原子価が $\mathrm{Fe}^{2+}, \mathrm{Cr}^{3+}, \mathrm{Ni}^{2+}$ と なり, $\mathrm{NaNO}_{3}$ 電解液の場合にはそれらの原子価が $\mathrm{Fe}^{3+}$, $\mathrm{Cr}^{6+}, \mathrm{Ni}^{2+}$ で溶出することをそれぞれ示唆している。な

Table 1 Current efficiency for stainless steel (SUS 304) dissolved in $\mathrm{NaCl}$ and $\mathrm{NaNO}_{3}$ electrolytes at $25^{\circ} \mathrm{C}$

\begin{tabular}{l|c|c|c|c|c}
\hline \hline \multirow{2}{*}{$\begin{array}{l}\text { Electro- } \\
\text { lyte }\end{array}$} & $\begin{array}{l}\text { Passed amount of } \\
\text { electricity }\left(\mathrm{C} / \mathrm{cm}^{2}\right)\end{array}$ & \multicolumn{3}{|c|}{ Current efficiency $(\%)$} \\
\hline \multirow{2}{*}{$100 \mathrm{~g} / l$} & 150 & 97.1 & $\mathrm{~B}$ & $\mathrm{C}$ & $\mathrm{D}$ \\
$\mathrm{NaCl}$ & 500 & 98.9 & 126.9 & 129.6 & 158.3 \\
& 1500 & 94.3 & 121.1 & 125.1 & 151.9 \\
\hline $200 \mathrm{~g} / l$ & 150 & 59.4 & 77.5 & 80.0 & 98.0 \\
$\mathrm{NaNO}_{8}$ & 500 & 63.4 & 80.3 & 85.8 & 99.3 \\
\hline
\end{tabular}

A : Calculated current efficiency assuming the dissolution as $\mathrm{Fe}^{2+}, \mathrm{Cr}^{8+}, \mathrm{Ni}^{2+}$

$\mathrm{B}: \mathrm{Fe}^{2+}, \mathrm{Cr}^{6+}, \mathrm{Ni}^{2+}, \mathrm{C}: \mathrm{Fe}^{8+}, \mathrm{Cr}^{3+}, \mathrm{Ni}^{2+}, \mathrm{D}: \mathrm{Fe}^{3+}$ $\mathrm{Cr}^{8+}, \mathrm{Ni}^{2+}$

Current density : $10 \mathrm{~A} / \mathrm{cm}^{2}$ 
お，両電解液中における沈殿物（金属水酸化物）の色は それぞれ異なり, $\mathrm{NaNO}_{3}$ では赤カッ色を示し， $\mathrm{NaCl}$ は灰緑色，黒色を経て赤カッ色になる。

\section{2 雷流密度および液溇度の影䇾}

Fig. 3 および 4 に, $500 \mathrm{C} / \mathrm{cm}^{2}$ の通電量で溶解させ たとき，実際に溶出した金属イオンの原子価を種々仮定 して計算した電気量とそのときの溶解電流密度および液 の濃度との関係を示す. 電流密度および液濃度が増加し

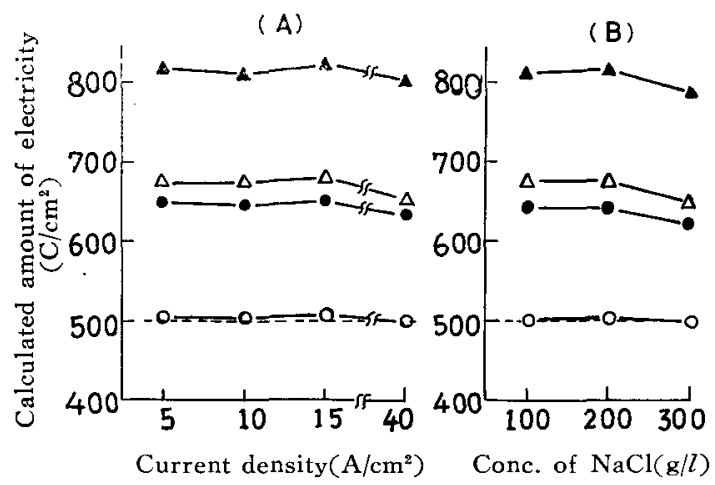

Fig. 3 Comparison between passed and calculated amounts of electricity as a function of current density (A), and concentration of $\mathrm{NaCl}(\mathrm{B})$ at $25^{\circ} \mathrm{C}$

$O$ : Calculated amount of electricity assuming the dissolution as $\mathrm{Fe}^{2+}, \mathrm{Cr}^{3+}, \mathrm{Ni}^{2+}$

- $: \mathrm{Fe}^{2+}, \mathrm{Cr}^{8+}, \mathrm{Ni}^{2+}, \triangle: \mathrm{Fe}^{3+}, \mathrm{Cr}^{8+}, \mathrm{Ni}^{2+}$

$\triangle: \mathrm{Fe}^{3+}, \mathrm{Cr}^{6+}, \mathrm{Ni}^{2+}, \ldots--$ : Passed amount of electricity

(A) : $100 \mathrm{~g} / \mathrm{l} \mathrm{NaCl}$, (B) $: 10 \mathrm{~A} / \mathrm{cm}^{2}$

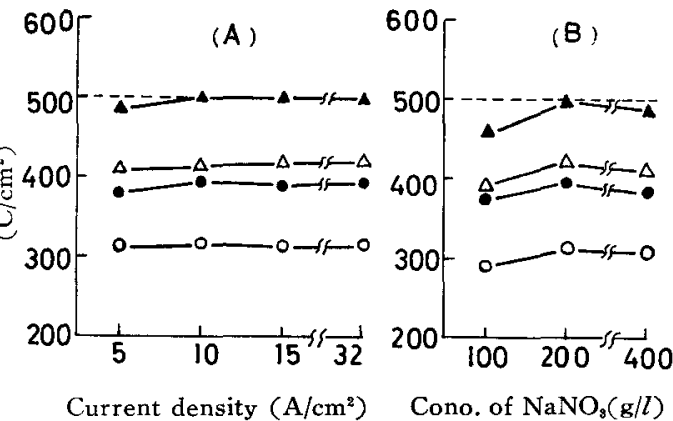

Fig. 4 Comparison between passed and calculated amonts of electricity as a function of current density (A), and concentration of $\mathrm{NaNO}_{3}$ at $25^{\circ} \mathrm{C}$

$\mathrm{O}$ : Calculated amount of electricity assuming the dissolution as $\mathrm{Fe}^{2+}, \mathrm{Cr}^{8+}, \mathrm{Ni}^{2+}$

- $: \mathrm{Fe}^{2+}, \mathrm{Cr}^{6+}, \mathrm{Ni}^{2+}, \triangle: \mathrm{Fe}^{3+}, \mathrm{Cr}^{3+}, \mathrm{Ni}^{2+}$

: $\mathrm{Fe}^{\mathrm{a+}}, \mathrm{Cr}^{\mathrm{bt}}, \mathrm{Ni}^{2+},----$ : Passed amount of electricity

(A) $: 200 \mathrm{~g} / l \mathrm{NaNO}_{3}$, (B) $: 10 \mathrm{~A} / \mathrm{cm}^{2}$
ても, $\mathrm{NaCl}$ の場合は溶出金属イオンの原子価が $\mathrm{Fe}^{2+}$, $\mathrm{Cr}^{3+}, \mathrm{Ni}^{2+}, \mathrm{NaNO}_{3}$ の場合には $\mathrm{Fe}^{3+}, \mathrm{Cr}^{6+}, \mathrm{Ni}^{2+}$ と仮 定した場合が最もよく理論值上計算值が一致する，この ことは溶出金属イオンに対する計算電気量と通電量との. 比較から容易に推定される．才なわち，他の溶出金属イ オンの価数で注，その電気量が通電量 $500 \mathrm{C} / \mathrm{cm}^{2}$ に比 較して約 $\pm 20 \%$ 以上も異なった值を示している。

\section{3 温度依存性}

Fig. 5 および 6 は電解液の温度を変えた場合, 溶出 金属イオンの原子価を種々仮定して計算した電気量と実 際に通電した電気量を示す. $\mathrm{NaCl}$ の場合，溶出金属イ

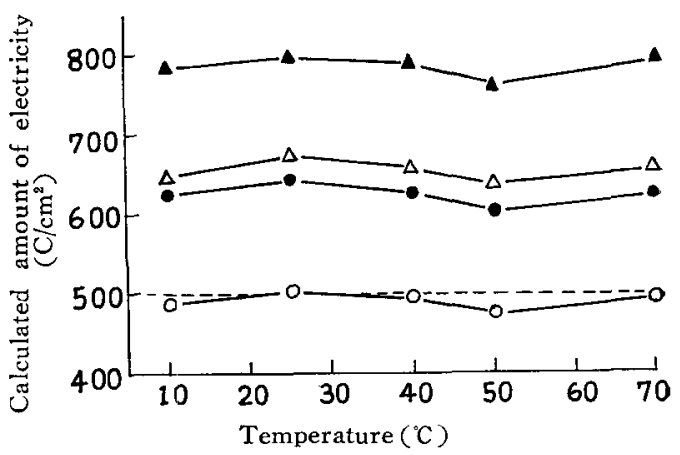

Fig. 5 Conparison between passed and calculated amounts of electricity as a function of temperature in $100 \mathrm{~g} / l \mathrm{NaCl}$ solution

$\mathrm{O}$ : Calculated amount of electricity assuming the dissolution as $\mathrm{Fe}^{2+}, \mathrm{Cr}^{2+}, \mathrm{Ni}^{2+}$

: $\mathrm{Fe}^{2+}, \mathrm{Cr}^{6+}, \mathrm{Ni}^{2+}, \triangle: \mathrm{Fe}^{3+}, \mathrm{Cr}^{3+}, \mathrm{Ni}^{2+}$

$\Delta: \mathrm{Fe}^{3+}, \mathrm{Cr}^{6+}, \mathrm{Ni}^{2+},----:$ Passed amount of electricity, Current density : $8.5 \sim 13 \mathrm{~A} / \mathrm{cm}^{2}$

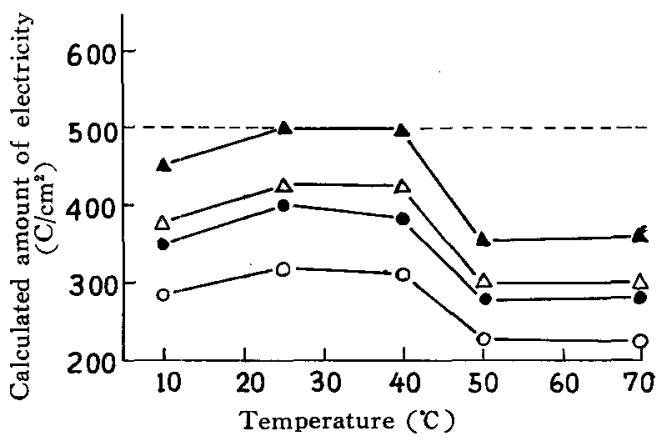

Fig. 6 Comparison between passed and calculated amounts of electricity as a function of temperature in $200 \mathrm{~g} / l \mathrm{NaNO}_{3}$ solution

$\mathrm{O}$ : Calculated amount of electricity assuming the dissolution as $\mathrm{Fe}^{2+}, \mathrm{Cr}^{8+}, \mathrm{Ni}^{2+}$

: $\mathrm{Fe}^{2+}, \mathrm{Cr}^{8+}, \mathrm{Ni}^{2+}, \triangle: \mathrm{Fe}^{8+}, \mathrm{Cr}^{8+}, \mathrm{Ni}^{2+}$

$\triangle: \mathrm{Fe}^{8+}, \mathrm{Cr}^{6+}, \mathrm{Ni}^{2+}, \ldots--$ : Passed amount of electricity, Current density : $5 \sim 10 \mathrm{~A} / \mathrm{cm}^{2}$ 
オンの原子価は液温度が変化しても Fig. 3 上同様な価 数を示すことが, 計算電気量と通電量との比較によって 確認される. 他方, $\mathrm{NaNO}_{3}$ の場合は低温度 $10^{\circ} \mathrm{C}$ 抢よ び高温度 $50 \sim 70^{\circ} \mathrm{C}$ において金属の溶出量が減少し, ア ノードからガス（酸素）の発生が顕著になる。このため $\mathrm{Fe}^{3+}, \mathrm{Cr}^{6+}, \mathrm{Ni}^{2+}$ と仮定して計算した電気量は通電量よ りも10 30\% ほど低い值を示す．これは上記の温度で は金属の溶解電流効率が 100\% 以下となり，電流の一部 がガスの発生に消費されているものと考えられる。

Fig. 7 は $\mathrm{NaCl}$ 電解液に $\mathrm{NaNO}_{3}$ を添加した場合, 溶出金属イオンの原子価を種々仮定して計算した電気量 の $\mathrm{NaNO}_{3}$ 添加濃度による変化を示す.この結果から,

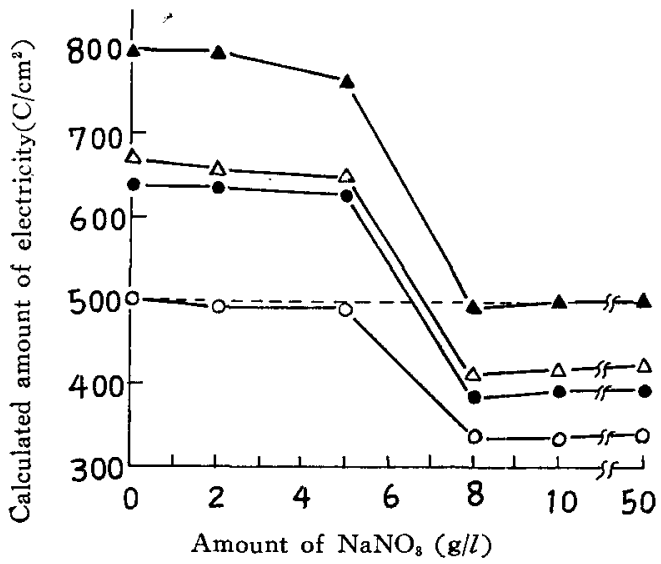

Fig. 7 Comparison between passed and calculated amounts electricity as a function of amount of $\mathrm{NaNO}_{3}$ added into $100 \mathrm{~g} / \mathrm{l} \mathrm{NaCl}$ solution, at $25^{\circ} \mathrm{C}$

$O$ : Calculated amount of electricity assuming the dissolution as $\mathrm{Fe}^{2+}, \mathrm{Cr}^{3+}, \mathrm{Ni}^{2+}$

: $\mathrm{Fe}^{2+}, \mathrm{Cr}^{6+}, \mathrm{Ni}^{2+}, \triangle: \mathrm{Fe}^{8+}, \mathrm{Cr}^{8+}, \mathrm{Ni}^{2+}$

$\triangle: \mathrm{Fe}^{8+}, \mathrm{Cr}^{6+}, \mathrm{Ni}^{2+},----:$ Passed amount of electricity, Current density : $10 \mathrm{~A} / \mathrm{cm}^{2}$

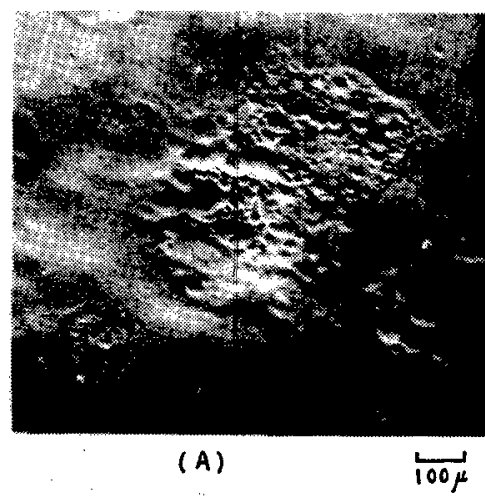

添加浱度が $2,5 \mathrm{~g} / l$ のときには溶出金属イオンが $\mathrm{Fe}^{2+}$, $\mathrm{Cr}^{3+}, \mathrm{Ni}^{2+}$ となるが, $8 \mathrm{~g} / \mathrm{l}$ 以上になると $\mathrm{Fe}$ および $\mathrm{Cr}$ の溶出原子価は $\mathrm{Fe}^{3+}, \mathrm{Cr}^{6+}$ に移行することがわかる. このような溶出金属イオンの価数変化は，電解後の液中 に $\mathrm{Fe}(\mathrm{OH})_{3}$ とみられる㤸ッ色の沈殿と $\mathrm{CrO}_{4}{ }^{2-}$ (黄 色）の生成加認められる。

\section{4 溶解面の表面状態}

Photo. 1 は $\mathrm{NaCl}$ および $\mathrm{NaNO}_{3}$ 電解液中でステン レス鋼をアノード溶解させた後の表面を走查型電子頙微 鏡によって観察した結果を示す. $\mathrm{NaCl}$ の場合法金属光 沢が電解前と变わらずに保持されるが, 部分的には多数 のピット発生が見られる。これに対して， $\mathrm{NaNO}_{3}$ を使 用した場合には全表面が灰色を呈し，光沢面はほとんど 見られない．また前者は電極周辺部での溶解が顕著であ るのに対して，後者は表面全体が比較的均一に溶解する 傾向を示している．以上のような各電解液に扔汀る表面 状態の相異は，今回の実験範囲内ではすべて同じ結果が 得られている. Fig. 8 は上記の電解液によって得られ た溶解面の粗度曲線を示す. $\mathrm{NaCl}$ を電解液とした場合 $\mathrm{NaNO}_{3}$ に比較して溶解面が非常になめらかであるが， $\mathrm{NaNO}_{3}$ では逆に著しく粗化していることが認められる.
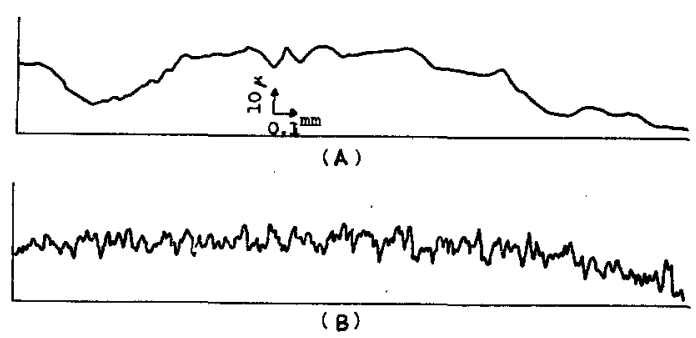

Fig. 8 Profile traces of stainless steel surface after anodic dissolution in $100 \mathrm{~g} / l \mathrm{NaCl}$ (A) and $200 \mathrm{~g} / \mathrm{l} \mathrm{NaNO}_{3}$ (B) solutions at $25^{\circ} \mathrm{C}$, current density of $10 \mathrm{~A} / \mathrm{cm}^{2}$

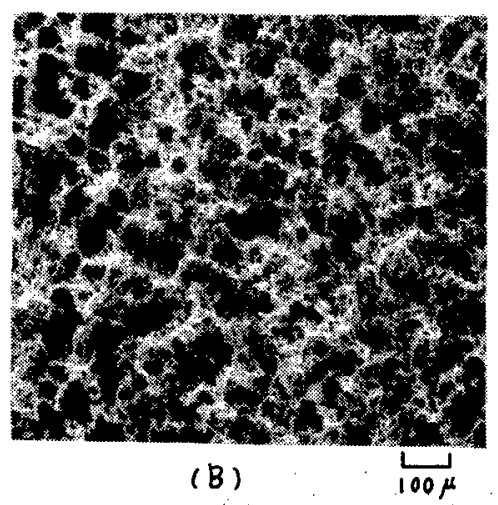

Photo. 1 Scanning electron micrographs of stainless steel surface after anodic dissolution in $100 \mathrm{~g} / \mathrm{l}$ $\mathrm{NaCl}$ (A) and $200 \mathrm{~g} / \mathrm{l} \mathrm{NaNO}_{3}$ (B) solutions at $25^{\circ} \mathrm{C}$, current density of $10 \mathrm{~A} / \mathrm{cm}^{2}$ 


\section{5 アノード分極曲線}

Fig. 9 は $\mathrm{NaCl}, \mathrm{NaNO}_{3}$ および $\mathrm{NaCl}+\mathrm{NaNO}_{3}$ の 電解液中におけるステンレス鋼の定電位アノード分極曲 線を示す.

この測定は試料電極をあらかじめ $-1.0 \mathrm{~V}$ (S.C.E.)

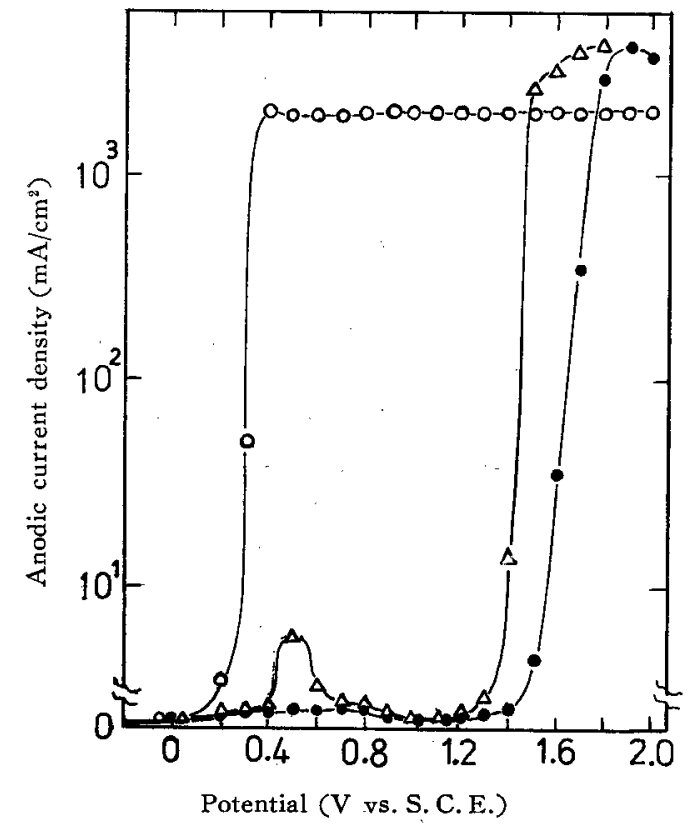

Fig. 9 Anodic polarization curves of stainless steel (SUS 304) in various solutions at $25^{\circ} \mathrm{C}$

$\mathrm{O}: 100 \mathrm{~g} / / \mathrm{NaCl}, \quad: 200 \mathrm{~g} / / \mathrm{NaNO}_{3}$

$\triangle: 100 \mathrm{~g} / l \mathrm{NaCl}+10 \mathrm{~g} / l \mathrm{NaNO}_{\mathrm{s}}$

で 10 分間カソード還元してから，アノード方向へ手動 により $100 \mathrm{mV}$ 間隔で分極させ，各電位で 2 分間保持 してそのときの電流を测定する方法を用いている。これ より, $\mathrm{NaCl}$ では $0.2 \mathrm{~V}$ 付近からアノード電流が急激に 上昇し始める.これは $\mathrm{Cl}^{-}$イオンが存在しない $\mathrm{NaNO}_{3}$ の場合汇は当然不働態領域にあるので，この電流の増加 は $\mathrm{Cl}^{-}$イオンによってステンレス鋼表面に孔食が発生 し，この孔食から金属功溶解するためと考えられる。さ らに0.4V からは電流密度が約 $2 \mathrm{~A} / \mathrm{cm}^{2}$ となって, ほ とんど変化しなくなることが認められる．ガス(酸素) の発生は認められず，分極後のアノード表面には大小の 孔食が広い範囲にわたって観察される。一方, $\mathrm{NaNO}_{3}$ では安定な不働態領域が広範囲に存在し, 電流は $1.4 \mathrm{~V}$ を越えると過不働態溶解に基づいて上昇し始める。がス (酸素) の発生は $1.6 \mathrm{~V}$ および $1.7 \mathrm{~V}$ が最も顕著で, これより電位が貴方向へ移行するにしたがって非常に少 くなる.また $\mathrm{NaCl}+\mathrm{NaNO}_{3}$ の場合には孔食溶解とそ の再不働態化が現われ，電流は $1.2 \mathrm{~V}$ 付近より過不働 態溶解に基づいて急上昇する。.
これらの結果から，ステンレス䤡は $\mathrm{NaCl}$ の場合には 孔食溶解が連なって全表面がピットの底のような状態で 活性溶解（または電解研摩型溶解）をしており， $\mathrm{NaNO}_{3}$ では分極測定後の溶液が黄色を呈し, $\mathrm{CrO}_{4}{ }^{2-}$ の生成を 示すなど過不働態領域で溶解が行われるものと考えられ る、一般に過不㗢態溶解については, Cr の高原子価の可 溶性酸化物走生ずるようなア)ード反応 $\left(\mathrm{Cr}+4 \mathrm{H}_{2} \mathrm{O} \rightarrow\right.$ $\left.\mathrm{CrO}_{4}{ }^{2}+8 \mathrm{H}^{+}+6 e^{-}\right)$の起ったためで, $\mathrm{Cr}$ は 6 俩の $\mathrm{CrO}_{4}{ }^{2-}$ となって溶解するために電流が急堌するものと考えられ ている、また，奥山らりによれば過不働態では $\mathrm{Cr}_{2} \mathrm{O}_{3}$ か $5 \mathrm{CrO}_{3}$ に酸化され, 過不働態溶解は $\mathrm{CrO}_{3}$ の化学溶解 に基つくくものとされている. 本実験における過不働態挙 動も同様な機棈によるものと考えられる. なお, $\mathrm{CrO}_{2}{ }^{2-}$ の生成は実際以行われる電解加工条件でも確認されてお り,このこと注本研究における溶出金属イオンの価数推 定結果と非常によく一致している.

\section{4 結 論 (Conclusion)}

高濃度の $\mathrm{NaCl}, \mathrm{NaNO}_{3}$ および $\mathrm{NaCl}+\mathrm{NaNO}_{3}$ の各 電解液中におけるステンレス鋼のアノード溶解挙動を調 ベ，次の結論を得た。

1）溶出金属イオンの価数は, $\mathrm{NaCl} て ゙ は ~ \mathrm{Fe}^{2+}, \mathrm{Cr}^{3+}$, $\mathrm{Ni}^{2+}$ になるが, $\mathrm{NaNO}_{3}$ では $\mathrm{Fe}^{3+}, \mathrm{Cr}^{6+}, \mathrm{Ni}^{2+}$ にな る.この場合金属の溶解電流效率はいずれも $100 \%$ に近 似した值を示す。また，溶解面は両液閒で顕著な相異が 認められる。

2) $\mathrm{NaCl}$ 電解液に $\mathrm{NaNO}_{3}$ を添加した場合, $8 \mathrm{~g} / l$ の添加量から溶出金属イオンの価数か゚ $\mathrm{Fe}^{3+}, \mathrm{Cr}^{6+}$ にな って高原子洒へ、移行する。

3） $\mathrm{NaCl}$ 溶液中でのステンレス鋼のアノード分極典 線には活性溶解領域(孔食を含む)が存在するが, $\mathrm{NaNO}_{3}$ 溶液では比較的安定な不働態および過不働態領域が認め られる。

4）電解加工液として， $\mathrm{NO}_{3}$ - イオン含有する溶液を 用いた場合ステンレス鍓中のクロムは有害な六価クロム となり，その大部分は液中に存在するが，一部は電解ス ラッジ(金属水酸化物, 酸化物)にも吸着されるので, こ れらの加工廃萧物処理に対する公害対策が必要である。

終わりに, 走查型電子影微鏡写真についてご協力いただいた 機械技術研究所メカニズム課，斎藤慶子技官に厚く感謝しま 寸. <1446> (Received May 21, 1974)

\section{文藏}

1) J.P. Hoare, J. Electrochem. Soc. 117, 142 (1970)

2) J.P. Hoare, K-W. Mao, A.J. Wallace, Corrosion 21, 211(1971).

3) K-W. Mao, J. Electrochem. Soc. 118, 1876 (1971).

4) K-W. Mao, M.A. LaBoda, J.P. Hoare, ibid. 119, 419 (1972).

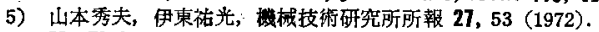

6) K. Chikamori, H. Yamamoto, S. Ito, "Proceedings of International Confereace on Production Engineering”, p. 68 (1974), Tokyo.

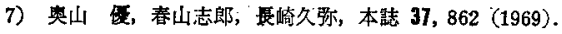

